\title{
Increased risk of cancer at multiple sites after gastric surgery for peptic ulcer
}

\author{
C P J CAYGILL, M J HILL, C N HALL, J S KIRKHAM, AND T C NORTHFIELD \\ From the Norman Tanner Gastroenterology Unit, St James Hospital, Balham, PHLS Communicable Disease \\ Surveillance Centre, Central Public Health Laboratories, London, and Bacterial Metabolism Research \\ Laboratory, PHLS-CAMR, Porton Down, Salisbury, Wiltshire
}

SUMmaRY Of 5018 patients who had undergone gastric surgery at St James Hospital, Balham, at least 25 years ago, death certificates have been received for 2768 , whilst 1746 patients are still alive and are flagged (Office of Populations, Censuses and Surveys (OPCS) will notify us of their death and its cause) and only 504 could not be traced. Mortality from cancers of various organs has been determined using a 'years at risk' calculation in five year bands. There was no increase in mortality risk from any cancers during the first 15 postoperative years, but from 20 years after operation there was a significant excess risk not only of cancer of the stomach $(4 \cdot 5$-fold $)$, but also of the large bowel $(1 \cdot 6$-fold), bronchus $(3 \cdot 9$-fold $)$, pancreas $(4 \cdot 0$-fold $)$, biliary tract $(9 \cdot 1$-fold $)$, oesophagus $(2 \cdot 3$-fold $)$, bladder $(2 \cdot 4$-fold $)$, breast $(4 \cdot 0$-fold $)$, and cancer of all sites $(3 \cdot 3$-fold $)$. These findings are consistent with the production in the operated-upon stomach of circulating carcinogens with a 20 year latency period.

There have been a number of studies relating surgery for peptic ulcer to the subsequent risk of gastric cancer, some showing an association ${ }^{1-4}$ and some not. ${ }^{57}$ Many possible explanations for this have been suggested, but our large study ${ }^{\sharp}$ of 2577 duodenal ulcer patients and 1385 gastric ulcer patients showed that whereas more than 20 years postsurgery both groups of patients had an excess risk of gastric cancer, during the first 20 postoperative years there was an excess risk in the gastric ulcer patients but a decreased risk in duodenal ulcer patients. Thus, an association between gastric surgery and gastric cancer in either direction or no association at all could be expected depending solely on the relative proportion of duodenal ulcer and gastric ulcer patients, and on the length of follow up.

A possible mechanism for this increased carcinogenesis is that surgery results in gastric hypoacidity leading to bacterial overgrowth with consequent production of carcinogens. A hypothesis involving nitrite and $\mathrm{N}$-nitroso compounds has been sug-

Address for correspondence: Dr C P J Caygill, PHLS Communicable Disease Surveillance Centre, Central Public Health Laboratories, 61 Colindale Ave. London NW9 5HT.

Received for publication 8 January 1987. gested $^{41 "}$ and there is some experimental evidence in support of this. ${ }^{11-13}$ Such carcinogens could act distally as well as locally, and we therefore investigated 348 Polya partial gastrectomy patients ${ }^{4}$ for increased risk of cancer at distal sites. This showed an increased risk of biliary tract and colorectal cancer.

In order to test this hypothesis further, we investigated the risk of mortality from cancer in a number of different sites (stomach, colorectum, bile tract, pancreas, lung, oesophagus bladder, and breast) in 5018 patients who had gastric surgery at St James Hospital, Balham between 1940 and 1960. An increased risk was found at all these sites, with a latency of approximately 20 years.

\section{Methods}

STUDY POPULATION

The study population was those patients treated surgically for peptic ulcer by Mr Norman Tanner and his colleagues at the Gastric Clinic, St James Hospital, Balham, between 1940 and 1960. The operations were either Bilroth I, Bilroth II (Polya) partial gastrectomy, or truncal vagotomy with either drainage or gastroenterostomy alone. The 5018 
patients were traced through the Office of Populations, Censuses and Surveys (OPCS). Death certificates were obtained for 2768 patients and coded by OPCS to the 8th revision of the International Classification of Diseases (ICD) codes to coincide with the period of the majority of deaths. One thousand seven hundred and forty six are still alive, and are flagged at OPCS for subsequent notification of death and its cause; 504 could not be traced (either because they had emigrated, or insufficient personal information was available, or were not registered with the Family Practitioners Committee). As far as can be determined from the information in their hospital notes, the group did not differ from the study population in age at operation, sex, type of ulcer, etc. The patients' information is stored on a Sirius Computer using programs designed by the Computer Services Department of the Public Health Laboratory Service.

\section{CALCULATION}

A computer program, using mortality data (1971-8) for SW Thames Region in five year age groups up to age $85+(\mathrm{OPCS}$, unpublished data) permitted the calculation of the cancer risk in each patient taking account of sex, age at operation, etc, expressed as 'person - years at risk' in five year bands from the age at operation. The probability levels were calculated using the Poisson or normal approximation to the binomial distribution as appropriate. ${ }^{1+15}$ The SW Thames Region was chosen because that was the final residence for $68 \%$ of the study population; the period 1971-8 was the closest available to the time of most of the deaths in the study.

\section{Results}

We have already reported ${ }^{*}$ that for gastric cancer there was no increased risk within the first 20 years after operation but a marked increase thereafter. This was also true for cancer at other sites except lung, where the increase in risk began to be manifest at 15 years.

Table 1 shows mortality from various cancers during the first 20 postoperative years, and for 20 or more years after operation, both in the whole study

Table 1 Mortality from a number of different cancers after gastric surgery for ulcers by ulcer site

\begin{tabular}{|c|c|c|c|c|c|c|c|c|}
\hline \multirow[b]{2}{*}{ Cancer Site } & \multirow[b]{2}{*}{ Site of ulcer } & \multirow[b]{2}{*}{ patients $(n)$} & \multicolumn{3}{|c|}{$0-19$ years after operation } & \multicolumn{3}{|c|}{$20+$ years after operation } \\
\hline & & & $O$ & $E$ & $O / E$ & $O$ & $E$ & $O / E$ \\
\hline \multirow[t]{3}{*}{ Gastric } & DU & 2577 & 9 & $20 \cdot 9$ & $0 \cdot 4^{*}$ & 20 & $5 \cdot 5$ & $3 \cdot 6+$ \\
\hline & GU & 1385 & 32 & $12 \cdot 0$ & $2 \cdot 7 \dagger$ & 12 & $2 \cdot 2$ & $5 \cdot 5 \dagger$ \\
\hline & All patients & 4514 & 44 & $35 \cdot 8$ & $1 \cdot 2$ & 37 & $8 \cdot 3$ & $4.5 \dagger$ \\
\hline \multirow[t]{3}{*}{ Colorectal } & DU & 2577 & 23 & $28 \cdot 5$ & $0 \cdot 8$ & 6 & $8 \cdot 0$ & 0.8 \\
\hline & GU & 1385 & 8 & $17 \cdot 1$ & $0.5^{*}$ & 11 & $3 \cdot 7$ & $3 \cdot 0^{*}$ \\
\hline & All patients & 4514 & 37 & $53 \cdot 4$ & $0.7 \ddagger$ & 20 & $12 \cdot 6$ & $1 \cdot 6 \ddagger$ \\
\hline \multirow[t]{3}{*}{ Biliary tract } & DU & 2577 & 4 & $1 \cdot 6$ & $2 \cdot 5$ & 2 & $0 \cdot 4$ & $5 \cdot 1$ \\
\hline & GU & 1385 & 1 & $1 \cdot 0$ & $1 \cdot 0$ & 3 & 0.2 & $15 \cdot 8^{*}$ \\
\hline & All patients & 4514 & 6 & $3 \cdot 1$ & 1.9 & 6 & 0.7 & $8 \cdot 6 \dagger$ \\
\hline \multirow[t]{3}{*}{ Breast (female only) } & DU & 438 & 5 & $6 \cdot 6$ & $0 \cdot 8$ & 5 & $1 \cdot 3$ & $4 \cdot 0^{*}$ \\
\hline & GU & 442 & 1 & $6 \cdot 6$ & $0.2 \div$ & 4 & 1.0 & $4 \cdot 0 \ddagger$ \\
\hline & All patients & 1014 & 7 & $15 \cdot 2$ & $0 \cdot 5 \ddagger$ & 10 & $2 \cdot 5$ & $4 \cdot 0^{*}$ \\
\hline \multirow[t]{3}{*}{ Pancreas } & DU & 2577 & 7 & $10 \cdot 2$ & 0.7 & 6 & $2 \cdot 5$ & $2 \cdot 4 \ddagger$ \\
\hline & GU & 1385 & 4 & $5 \cdot 9$ & 0.7 & 6 & $1 \cdot 0$ & $5 \cdot 8^{*}$ \\
\hline & All patients & 4514 & 13 & $18 \cdot 6$ & 0.7 & 15 & $4 \cdot 0$ & $3 \cdot 8^{*}$ \\
\hline \multirow[t]{3}{*}{ Ocsophagus } & DU & 2577 & 4 & $6 \cdot 5$ & $0 \cdot 6$ & 3 & 1.7 & $1 \cdot 8$ \\
\hline & GU & 1385 & 5 & $3 \cdot 7$ & 1.4 & 2 & 0.7 & $3 \cdot 0$ \\
\hline & All patients & 4514 & 9 & $11 \cdot 6$ & 0.8 & 6 & $2 \cdot 6$ & $2 \cdot 3 \neq$ \\
\hline \multirow[t]{3}{*}{ Bladder } & DU & 2577 & 6 & 9.9 & $0 \cdot 6$ & 6 & $2 \cdot 8$ & $2 \cdot 2$ \\
\hline & GU & 1385 & 3 & $6 \cdot 2$ & 0.5 & 3 & $1 \cdot 2$ & $2 \cdot 5$ \\
\hline & All patients & 4514 & 10 & $17 \cdot 9$ & $0 \cdot 6 \ddagger$ & 11 & $4 \cdot 5$ & $2 \cdot 4^{*}$ \\
\hline \multirow[t]{3}{*}{ Lung } & DU & 2577 & 102 & $86 \cdot 0$ & $1 \cdot 2$ & 75 & $24 \cdot 4$ & $3 \cdot 1+$ \\
\hline & GU & 1385 & 80 & $57 \cdot 8$ & $1 \cdot 4^{*}$ & 56 & $9 \cdot()$ & $6 \cdot 2+$ \\
\hline & All patients & 4514 & 215 & $172 \cdot()$ & $1 \cdot 3^{*}$ & 146 & $37 \cdot 5$ & $3 \cdot 9+$ \\
\hline \multirow[t]{3}{*}{ All sites } & DU & 2577 & 192 & $236 \cdot 7$ & $0.8^{*}$ & 158 & $61 \cdot 8$ & $2 \cdot 6+$ \\
\hline & GU & 1385 & 165 & $143 \cdot()$ & $1 \cdot 2$ & 115 & $25 \cdot 4$ & $4.5^{\dagger}$ \\
\hline & All patients & 4514 & 467 & $470 \cdot 5$ & $1 \cdot 0$ & 323 & $98 \cdot 6$ & $3 \cdot 3 \dagger$ \\
\hline \multirow[t]{3}{*}{ All non-neoplastic disease $\$$} & DU & 2577 & 532 & 978.9 & $0.5 \div$ & 496 & $3(0) \cdot 2$ & $1.7 t$ \\
\hline & GU & 1385 & 475 & $628 \cdot 9$ & $0.8+$ & 294 & $159 \cdot 5$ & $1.8 \dagger$ \\
\hline & All patients & 4514 & 1201 & $1844 \cdot 7$ & $0.7 \dagger$ & 845 & $532 \cdot 0$ & $1.6+$ \\
\hline
\end{tabular}

${ }^{*} p<0 \cdot 01 ; \dagger p<0.001 ; \ddagger p<0 \cdot 05$. All other ratios $p>0 \cdot 05$. O - observed; E - expected. §Based on national mortality rates; all other expected rates are for $\mathrm{SW}$ Thames Region. 
population and separately in those for whom a diagnosis of a simple duodenal ulcer or gastric ulcer could be made. Unfortunately our program did not subdivide into five year bands beyond 20 years, and in any case the expected number of cases in such bands would have been small. It is possible, therefore, that the statistical significance of the results could have been even higher at $25+$ or $30+$ years, for example, than at $20+$ years. The 'all patients' group, in addition to the simple duodenal ulcer and gastric ulcer patients, also includes those whose peptic ulcer could not be clearly defined - for example, where the patient had both a duodenal ulcer and gastric ulcer, a stomach ulcer after gastroenterostomy, or an unspecified peptic ulcer. There were no statistically significant increases in mortality from most of these cancers in the first 20 years after operation, but subsequently a marked increase in mortality was observed from cancer of the colorectum, biliary tract, oesophagus, bladder, breast, pancreas, and lung as well as from gastric cancer and cancer of all sites. As many of these patients had a cholecystectomy at the time of their gastric surgery the risk of biliary tract cancer is an underestimate of the true risk. As can be seen in all cases the excess risk after surgery for gastric ulcer is either greater than, or equal to, that after duodenal ulcer, but never the reverse. The small increase in mortality from lung cancer (1.3fold) within the first 20 years is limited to the 15-20 year period. There was a slight but significant decrease in deaths from colorectal, breast and bladder cancers during the first 20 years. For all nonneoplastic disease there was a small decrease during the first 20 years (similar in magnitude to that of colorectal and pancreatic cancer) followed by a small excess risk subsequently.

Table 2 shows a breakdown for all cancers and all non-neoplastic disease by operation type as well as site of the original ulcer.

\section{Discussion}

The results presented here show that in this large population of 5018 gastric surgery patients there is an excess risk of cancer at a number of different sites.

For cancer of the biliary tract, pancreas and lung, as well as of the stomach, the mortality during the first 15-20 postoperative years was as expected, and a large excess was found in subsequent years. This was true also for cancer of all sites, even if lung cancer deaths were omitted. Thus, for these cancers there was an increase in the overall mortality. On the other hand, for cancers of the colorectum, bladderr, oesophagus and breast, as well as for non-neoplastic disease, there was no overall excess of mortality because the excess risk 20 or more years after operation was largely offset by a decrease in risk within the first 20 years, suggesting a delay in mortality from cancer in this patient group.

Some of the observations reported here have been made previously. Watt $e t a l^{2}$ observed an excess risk of cancer of the oesophagus, colorectum, pancreas, breast, and lung (although only the lung and colorectum were statistically significant) whilst Ross et $a l^{5}$ reported a statistically significant excess of cancer of the lung, pancreas, and colorectum. The size of our study and the length of follow up lias yielded statistically significant excess risks for all of the cancer sites observed by Watt $e t$ al. The common latency of 20 years suggests that they are unrelated to a common predisposition, such as smoking as suggested by Ross et al, ${ }^{5}$ that would have predated the surgery by many years, and are more likely to be related to an event occurring at the time of surgery.

Other sources of bias must also be considered. The $10 \%$ of untraced patients may well have had an increased mortality particularly within the first 20 years and thus the true observed mortality would be higher than that shown here. Table 3 shows a

Table 2 Mortality from cancer of all sites and from non-neoplastic disease by type of operation and site of original ulcer

\begin{tabular}{|c|c|c|c|c|c|c|c|c|c|c|c|c|c|c|}
\hline \multirow{3}{*}{ Optype } & \multirow{3}{*}{$\begin{array}{l}\text { Site of } \\
\text { ulcer }\end{array}$} & \multirow{3}{*}{$\begin{array}{l}\text { Patients } \\
\text { (n) }\end{array}$} & \multicolumn{6}{|c|}{ Cancer of all sites } & \multicolumn{6}{|c|}{ All non-neoplastic disease $\$$} \\
\hline & & & \multicolumn{3}{|c|}{$0-19$ years after operation } & \multicolumn{3}{|c|}{$20+$ years after operation } & \multicolumn{3}{|c|}{$0-19$ years after operation } & \multicolumn{3}{|c|}{$20+$ years after operation } \\
\hline & & & $O$ & $E$ & $O / E$ & $O$ & $E$ & $O / E$ & $O$ & $E$ & $O / E$ & $O$ & $E$ & $O / E$ \\
\hline B1 & DU & 113 & 9 & 10.9 & $0 \cdot 8$ & 5 & 2.9 & 1.7 & 29 & $45 \cdot 1$ & $0 \cdot 6^{*}$ & 14 & $16 \cdot 2$ & 0.9 \\
\hline B11 & DU & 1946 & 172 & 191.5 & 0.9 & 118 & $47 \cdot 8$ & $2 \cdot 5 \ddagger$ & 442 & $791 \cdot 6$ & $0.6 \ddagger$ & 412 & 236.9 & $1 \cdot 7 \ddagger$ \\
\hline VAG & DU & 518 & 21 & $34 \cdot 3$ & $0.6+$ & 35 & $11 \cdot 2$ & $3 \cdot 1 \ddagger$ & 61 & $142 \cdot 2$ & $0 \cdot 4 \ddagger$ & 70 & $47 \cdot 1$ & $1 \cdot 5 \ddagger$ \\
\hline All & DU & 2577 & 192 & $236 \cdot 7$ & $0 \cdot 8+$ & 158 & 61.9 & $2 \cdot 6 \ddagger$ & 532 & 978.9 & $0 \cdot 5 \ddagger$ & 496 & $300 \cdot 2$ & $1.7 \ddagger$ \\
\hline B1 & GU & 1040 & 120 & $107 \cdot 4$ & $1 \cdot 1$ & 71 & $18 \cdot 3$ & $3.9 \ddagger$ & 359 & $491 \cdot 0$ & $0.7 \ddagger$ & 208 & $119 \cdot 0$ & $1 \cdot 7 \ddagger$ \\
\hline B11 & GU & 340 & 44 & $35 \cdot 0$ & $1 \cdot 3$ & 42 & $7 \cdot 1$ & $5.9 \ddagger$ & 115 & 134.5 & 0.9 & 85 & 39.8 & $2 \cdot 1 \neq$ \\
\hline VAG & GU & 5 & 1 & 0.6 & 1.7 & 2 & $0 \cdot 0$ & - & 1 & 3.4 & $0.3^{*}$ & 1 & 0.7 & 1.4 \\
\hline All & GU & 1385 & 165 & 143.0 & $1 \cdot 2$ & 115 & $25 \cdot 4$ & $4 \cdot 5 \ddagger$ & 475 & 628.9 & $0.8 \ddagger$ & 294 & 159.5 & $1.8 \pm$ \\
\hline
\end{tabular}

${ }^{*} p<0.05 ; \nmid p<0.01 ; \neq p<0 \cdot 001$. All other ratios $p>0.05$. O - observed; $E$ - expected. $\$ B$ ased on national mortality rates; all other expected rates are for $\mathrm{SW}$ Thames Region. $\mathrm{GU}=$ gastric ulcer; $\mathrm{DU}=$ duodenal ulcer. 
Table 3 Standardised death rates using the population of 1951-1955 as the base

\begin{tabular}{lllrrr}
\hline Cancersite & $\begin{array}{l}\text { ICD } \\
\text { (8th rev.) }\end{array}$ & Sex & $1956-1960$ & $1961-1965$ & $1971-1974$ \\
& & & & & \\
\hline All sites & $140-239$ & $\mathrm{M}$ & 2301 & 2367 & 2479 \\
& & $\mathrm{~F}$ & 1848 & 1838 & 1918 \\
Oseophagus 150 & $\mathrm{M}$ & 59 & 58 & 68 \\
& & $\mathrm{~F}$ & 39 & 40 & 45 \\
Stomach & 151 & $\mathrm{M}$ & 353 & 323 & 270 \\
& & $\mathrm{~F}$ & 244 & 212 & 163 \\
Colon & 153 & $\mathrm{M}$ & 165 & 154 & 163 \\
& & $\mathrm{~F}$ & 217 & 201 & 196 \\
Rectum & 154 & $\mathrm{M}$ & 138 & 124 & 119 \\
& & $\mathrm{~F}$ & 98 & 92 & 88 \\
Pancreas & 157 & $\mathrm{M}$ & 88 & 94 & 106 \\
& & $\mathrm{~F}$ & 71 & 74 & 83 \\
Lung, etc. & 162,163 & $\mathrm{M}$ & 771 & 875 & 983 \\
& & $\mathrm{~F}$ & 116 & 145 & 217 \\
Bladder & 188 & $\mathrm{M}$ & 91 & 97 & 105 \\
& & $\mathrm{~F}$ & 36 & 35 & 37 \\
Breast & \multirow{2}{*}{174} & $\mathrm{~F}$ & 359 & 370 & 409 \\
\hline
\end{tabular}

OPĆS Series DHI No 3 Trends in Mortality 1951-1975. London: HMSO, 1978: 40.

comparison of the mortality rates at two points within the first 20 years of this study (1956-60 and 1961-5), compared with a representative part of our reference population. This could make a small difference to the number of expected cases at each site, but this would be insufficient to affect the conclusions.

Of the cancers reported here, oesophagus, gastric, and lung cancer are inversely related to socioeconomic status while colon and breast are weakly positively associated with social class. Our overall results are therefore highly unlikely to be because of any bias in the social class structure of the patient group studied, although the social class distribution of the duodenal ulcer cases may differ from that of the gastric ulcer's.

These patients tended to be under closer medical supervision, but the apparent excess risk of mortality from these diseases is only partially explicable in these terms. For example, it should be noted that the pattern of colorectal cancer mortality does not fit this model. The apparent effect of surgery on the risk of colorectal cancer is only observed in gastric ulcer and not in duodenal ulcer patients; within the gastric ulcer patients the apparent protection during the first 20 postoperative years is only observed in men whilst the subsequent excess risk was only observed in women. ${ }^{16}$ This might have implications for the role of diet as a promoter of cancers at these sites, because gastric surgery often leads to a change in eating patterns.

There is a possibility that the increased cancer risk is the result of some other predisposing factor common to both gastric surgery and the cancers described. For instance, peptic ulcer patients are often smokers, ${ }^{+}$and this could contribute to the increase in cancer of the lung and pancreas. If the increase was caused by such a common factor, there should be no decrease within the first 20 years after surgery, as seen here for colorectal, breast, and bladder cancer, but a steady increase in excess risk throughout the whole postoperative period.

The data on these 5018 patients are stored on a computer and further analyses will be carried out. These analyses should give more useful information concerning subsites - for example, whether the excess in biliary tract cancer is in the gall bladder or in the bile ducts; whether the excess colon cancer is in the proximal or distal portion, etc.

In carrying out long term clinical follow up of patients who have undergone gastric surgery, it should be borne in mind that the excess risk of developing cancer is not confined to the stomach; that this excess risk is not apparent until 20 years after the operation; and that in terms of the total number of cancers developing, the greatest risk is still for carcinoma of the bronchus (146/323 cancers causing mortality 20 or more years postoperative in the present study).

It is noteworthy that for all cancer sites the risk is greater in patients treated for gastric ulcer than in those treated for duodenal ulcer. We have already reported the excess risk of colorectal cancer ${ }^{+}$in pernicious anaemia patients and have also observed an excess of biliary tract cancers (unpublished data). The gastric ulcer patients reported here are likely to have had gastric atrophy and a raised gastric $\mathrm{pH}$ at the time of operation whereas this would have followed later in the duodenal ulcer patients. It is possible, therefore, that the excess risk in gastric ulcer compared with duodenal ulcer patients is related to the length of time for which the patients had been hypochlorhydric.

The excess risk, with the same latency, of cancer at a number of different sites is consistent with the action of circulating carcinogens, and therefore, with the aetiology of gastric cancer in hypoacidic patients proposed by Ruddell et al, ${ }^{4}$ although the carcinogens involved need not necessarily be $\mathrm{N}$-nitroso compounds.

We would like to thank the Cancer Research Campaign for financing this study. We would also like to thank Mrs Edna Burns and Mr Roger Knowles for abstracting information and handling the data, the Medical Records Department at St James Hospital for help with finding patient records, Public Health Laboratory Computer Services and Mr M Longyear for the computer software, and Mrs Janet Mortimer for statistical advice. Particular thanks are due to the staff of OPCS (Office of Population Censuses and Surveys) both at St Catherine's House, 
London and at the Central Registry, Southport, without whose enthusiastic help it would not have been possible to trace such a large proportion of the patients.

\section{References}

1 Stahlsberg H, Taksdal S. Stomach cancer following gastric surgery for benign conditions. Lancet 1971; ii: 1175-7.

2 Watt PCH, Patterson CC, Kennedy TL. Late mortality after vagotomy and drainage for duodenal ulcer. $\mathrm{Br}$ Med J 1984; 288: 1335-8.

3 Pickford IR, Craven JL, Hall R, Thomas G, Stone WD. Endoscopic examination of the gastric remnant 31-39 years after subtotal gastrectomy for peptic ulcer. Gut 1984; 25: 393-7.

4 Caygill C, Hill M, Craven J, Hall R, Miller C. Relevance of gastric achlorhydria to human carcinogenesis. In: O'Neill IK, Von Borstel RC, Miller CT, Long J, Bartsch H. eds. N-nitroso compounds: occurence, biological effects and relevance to human cancer. Lyon: IARC No. 57, 1984: 895-900.

5 Ross AHM, Smith MA, Anderson JR, Small WP. Late mortality after surgery for peptic ulcer. $N$ Engl J Med 1982; 307: 519-22.

6 Kalina TV, Kivilaakso E. Is the risk of stump cancer increased after partial gastrectomy? Scand J Gastroenterol 1983; 18: suppl 86: 35-6.
7 Sandler RS, Johnson MC, Holland KL. Risk of stomach cancer after gastric surgery for benign conditions: a case control study. Dig Dis Sci 1984; 29: 703-8.

8 Caygill CPJ, Hill MJ, Kirkham JS, Northfield TC. Mortality from gastric cancer following gastric surgery for peptic ulcer. Lancet 1986; i: 929-31.

9 Ruddell WSJ, Bone ES, Hill MJ, Blendis LM, Walters CL. Gastric juice nitrate: a risk factor for cancer in the hypochlorhydric stomach? Lancet 1976 ii: 1037-9.

10) Schlag P, Bockler R, Ulrich H, Peter M, Merkle P, Herfarth $\mathrm{CH}$. Are nitrate and $\mathrm{N}$-nitroso compounds in gastric juice risk factors for carcinoma in the operated stomach? Lancet 1980; i: 727-9.

11 Jones SM, Davies PW, Savage A. Gastric juice nitrate and gastric cancer. Lancet 1978; i: 1355.

12 Reed PI, Summers K, Smith PLR, et al. Effect of ascorbic acid treatment on gastric nitrate and $\mathrm{N}$-nitroso compound concentrations in achlorhydric subjects. [Abstract]. Gut 1983; 24: A492-3.

13 Hall CN, Cook A, Darkin D, et al. Evaluation of the nitrosamine hypothesis of gastric carcinogenesis in man. [Abstract]. Gut 1984; 25: A582.

14 Chatfield C. Statistics for technology. London, Penguin, 1970: 92-5.

15 Murdoch J, Barnes JA. Statistical tables for science, engineering and management. London: MacMillan, 1970: 8-13.

16 Caygill CPJ, Hill MJ, Kirkham JS, Northfield TC. Increased risk of colorectal cancer after gastric surgery. [Abstract]. Gut 1986: 27: A600-1. 